\title{
STORYTELLING AND DIGITAL ART AS A MEANS TO IMPROVE MULTILINGUAL SKILLS
}

\author{
Véronique Delplancq ${ }^{1}$, Ana Maria Costa ${ }^{1}$, Cristina Amaro Costa ${ }^{2}$, Emília Coutinho $^{3}$, \\ Isabel Oliveira $^{4}$, José Pereira ${ }^{1}$, Patricia Lopez Garcia ${ }^{5}$, Romain Gillain ${ }^{6}$, Susana Amante ${ }^{1}$, \\ Susana Fidalgo ${ }^{1}, \&$ Susana Relvas ${ }^{4}$ \\ ${ }^{1}$ Instituto Politécnico de Viseu, CI\&DEI (Portugal) \\ ${ }^{2}$ Instituto Politécnico de Viseu, CERNAS (Portugal) \\ ${ }^{3}$ Instituto Politécnico de Viseu, UICISA-E (Portugal) \\ ${ }^{4}$ Instituto Politécnico de Viseu (Portugal) \\ ${ }^{5}$ Universidad Autonóma de Barcelona, Eurola (Spain) \\ ${ }^{6}$ Instituto Politécnico de Leiria, CI\&DEI (Portugal)
}

\begin{abstract}
The use of storytelling and digital art as tools to understand a migrant family's life path will be in the center of an innovative methodology that will ensure the acquisition of multilingual skills and the development of plurilingual awareness, reinforcing the various dimensions of language (aesthetic and emotional, in addition to cognitive), in a creative, collaborative and interdisciplinary work environment. This is especially important among students who are not likely to receive further language training.

It is not yet clear how teachers can explore multilingual experiences of learners, both in terms of language learning dimensions but also related with the multiple cognitive connections and representations, as well as to the awareness of language diversity.

The JASM (Janela aberta sobre o mundo: línguas estrangeiras, criatividade multimodal e inovação pedagógica no ensino superior) project involves a group of students of the 1st cycle in Media Studies, from the School of Education of Viseu, who will work using photography, digital art and cultural communication, collecting information pertaining to diversified cultural and linguistic contexts of the city of Viseu (Beira Alta, Portugal), both in French and English, centered on a tradition or ritual of a migrant family.

Based on an interview, students write the story (in French and English) of the life of migrants and use photography to highlight the most relevant aspect of the migrant's family life. Using as a starting point an object associated with religion, tradition or a ritual, students create an animated film, in both languages. This approach will allow the exploration of culture and digital scenography, integrating in an innovative interdisciplinary pathway, digital art, multilingual skills and multicultural awareness. Students' learning progress and teacher roles are assessed during this process, using tests from the beginning to the end of the project.
\end{abstract}

Keywords: Pedagogical innovation, higher education, project-based learning, foreign languages and cultural diversity, multilingual and multimodal artistic creativity.

\section{Introduction}

The JASM project was conceived as a teaching-learning experience in foreign languages (FL) in Higher Education (HE), with students from the Media Studies degree at the Polytechnic Institute of Viseu, Portugal. It falls within the scope of pedagogical innovation in HE, for a holistic approach, combining several methodologies of active, incorporated and constructivist learning, such as project-based learning and research-based learning, which place the student at the centre of the teaching-learning process, in a multilingual, multicultural and interdisciplinary environment.

In recent decades, Higher Education (HE) has witnessed new challenges that arise from globalization, migrations and transits (Piccardo, 2013) and the exponential development of technologies, which demand high levels of competitiveness in the labour market. In this sense, the teaching-learning process requires innovation in its practices with the aim of increasing student motivation and developing successful strategies, adapting learning experiences to their goals and needs, in line with the complexity of the real world. 
In this new context, the role of the teacher has undergone radical changes, from a mere someone who conveys content $\mathrm{s} /$ he has become knowledge facilitator, promoting exchanges inside and outside the classroom. Following a socio-constructivist approach allows for autonomy in the teaching-learning process, with the student assuming the role of actor in his/her own learning process. In this sense, cooperation is encouraged by carrying out integrated tasks adapted to the real environment. In turn, project pedagogy facilitates access to research and promotes lasting knowledge. This new approach implies a progression in the learning activity and improves the student's accountability and motivation.

With a view to acquiring multilingual and multicultural skills, in the process of learning foreign languages, the JASM project aims at deepening knowledge and developing skills, understanding and accepting attitudes and values, promoting self-confidence and respect for others, stimulating and developing the understanding and acceptance of different socio-cultural universes.

\section{Enhancing multilingual skills through storytelling and digital art}

According to the Council Recommendation of 22nd May 2018, the European Union identifies eight key skills for lifelong learning, trying to manage the cultural diversity of today's societies and to promote interculturality in an increasingly plural and globalized world. This European reference framework secondly highlights the importance of multilingual skills, which "(...) define the ability to use different languages appropriately and effectively for communication." (p. C189 / 8), especially in intense global mobility contexts.

In fact, languages not only define individual identity, but are also part of a common heritage. They link peoples and cultures, promoting mutual understanding and the development of a common feeling of European identity. Therefore, according to Morgado (2019), it is important to realise that

(...) a language is a culture and [...] one of the key aspects of identity or cultural identification of any individual is the language. To want someone to give up their language, thinking through it or learning through it is equivalent to asking them to give up their culture and a core dimension of their identity. (2019: 20)

Thus, underlying the relevance of the acquisition of multilingual skills is the appreciation of cultural diversity, the interest and curiosity about different languages and the promotion of intercultural communication, positive attitudes, essentially resulting from the creation of the single market and the increasing mobility in the European Union, the advent of the knowledge society, emigration and globalization. In this context, multilingualism has acquired special prominence, in order to allow individuals and companies to take full advantage of the opportunities at hand. Thus, the first decade of this century saw the emergence of an inclusive language learning policy, respecting individual linguistic profiles, with the aim of valuing all languages, including the regional, minority or migrant ones, in parallel with the official languages of the different countries.

Also, the fact that the Barcelona European Council in 2002 established for each citizen the ambitious goal of learning two other languages in addition to their mother tongue, contributed to the development of an active policy concerning multilingualism, mostly aiming at encouraging language learning and enhancing linguistic diversity within society, fostering a sound multilingual economy and promoting social integration through better linguistic knowledge and the acceptance of other languages.

So, acknowledging that one currently inhabits a globalized world implies knowing how to facilitate a multilingual dialogue and to value it, being aware of the advantages and disadvantages of a lingua franca such as English, which facilitates communication, but limits plurilingual learning and relies on use of verbal and non-verbal intercomprehension strategies that allow people to understand one another. Therefore, it is important to have a critical knowledge of the role of languages and communication also in the educational contexts, trying to develop, within the scope of school practices, not only an intercultural sensitivity, but at the same time an ability for intercultural dialogue and communicative efficacy, enabling empathy with those who speak other languages and have different worldviews.

A Curriculum based on multilingualism-inspired pedagogy privileges collaborative work and minimises barriers between languages (Piccardi, 2013: 604). In this case, "knowledge, skills, and the ability to learn are transversal and transferable across languages. Synergies would be created between languages with the purpose of reaching a common higher goal" (Piccardo, 2013: 604). In this sense, the development of multilingual skills through digital storytelling represents an asset in language teaching, allowing the construction of different realities, cultures and meanings. According to Reinders (2011:1) "The power of stories is such that many anthropologists, psychologists, and other scientists see it as being at the core of what makes us human". On the other hand, Valença and Tostes (2019) stress that telling stories has always been a form of transmission of concepts, values, ideas and images of the world, focussing mainly on human 
experiences and behaviours. If the mastery of different languages contributes to a global communication, storytelling as an educational tool allows for sharing experiences that can bring together different cultures.

Digital storytelling is, according to Robin (2006), the combination of storytelling with the use of digital multimedia, such as images, audio, and video. Soundtrack allows the recording of dialogues and the inclusion of musical moments that give expressiveness to the story told. In order to build a narrative combined with a soundtrack, students need to consider different issues, starting from the characters' point of view, social context and the emotions portrayed (Robin, 2006). Furthermore, students have the opportunity to express their thoughts, taking advantage of this experience to express their impressions on the story, and the impact it has on them. Storytelling favours, in this sense, the development of linguistic, discursive, strategic, sociolinguistic and intercultural skills. Expressing individual life worlds through narrative forms, multilingual digital storytelling (MDST) elicits collaborative work and the development of transversal linguistic competences (Anderson, Chung, Macleroy, 2018: 197). Thus, given the cultural authenticity and thematic diversity conveyed by storytelling, it provides learning contexts of an informative / cognitive nature (linguistic and cultural), as well as of a formative / educational nature (emotional, social, moral and aesthetic) essential to the holistic well-being of the student.

As a motivating strategy, storytelling contributes to the development of an emotional relationship with the foreign language, helping to overcome difficulties in a constructive way. Storytelling will allow the students to consider concepts and values and to express them in a more comprehensive way (Reinders, 2011). An additional benefit that digital storytelling offers, is the possibility of sharing the results both with other students and teachers, obtaining feedback, either to show that the point of view is well expressed and the message conveyed has been correctly interpreted by the student (Robin, 2006).

\section{The JASM project,}

The JASM project involved 20 students from the Media Studies degree course at the School of Education of the Polytechnic Institute of Viseu (Portugal). The study plan of the said course includes curricular units within the fields of FL, photography, digital art and intercultural communication. Professional opportunities range from media, media production, organization and information management, institutional and organizational communication, followed by a detailed study of the most illustrative aspects related to the culture and language of each country. This task allowed for research-based learning, crossing direct observation methods and data resulting from interviews.

In addition to the project, seminars were delivered by an expert in the fields of photography and digital art, to support the students' tasks. The first was carried out at the beginning of the experiment, in order to raise student awareness about the documentary value of photography. The second, put into practice later, focused on the potential of the Korsakow platform, fostering key components such as interdisciplinarity, the hybrid language of digital art and the use of communication technologies.

With regard to the field work, the first task consisted in identifying and locating immigrants representing previously selected nationalities, residing in the city. To this end, social networks helped to exchange information and, in addition, the Local Support Centre for Migrants Integration facilitated some contacts. The purpose of the first contact was to present the project and conduct an interview, thus allowing for the students to rely on their training profile to develop and master professional skills.

In addition, the students created a photographic record with the purpose of documenting important aspects of the interviewees' path, highlighting facets of their personalities. Subsequently, the students recorded the immigrants' life stories in writing. These task results were also discussed in the FL classes and were subject to evaluation.

The last step consisted in choosing a particular object or tradition with significant meaning for the immigrant, problematizing an aspect of the immigrants' culture. This project stage was recorded using the language of animation films. Digital scenography consisted in the development of a storyboard of fictional stories created by the students. Photographs previously taken were used and further research was carried out to ensure a more reliable illustration of the fictionalized narratives. As closure to the project, all the material produced, in different media and languages, was organized in the Korsakow system, resulting in a dynamic and interactive documentary, under the direction of a specialist in digital art.

The final results of this research work and the consequent investigative inquiries were fully addressed by the students and presented to the class and the teachers involved, both in French and English. All details of this project are available on the JASM website and displayed on social networks and have been the subject of exhibitions, presentations at events and publication in an e-book. 


\subsection{Assessment}

The constraints resulting from the pandemic which affected the period of implementation of the project required a revision of the outlined methodology. Assessment was based on a mixed evaluation method. Quantitative data were collected at the beginning of the process, using comprehension, oral and written tests. A language level test was applied, in each FL, to the group of students involved (20) and to the rest of the classmates (12). The tests, inspired by the DELF, DALF and TOEFL formats, were developed according to the levels of the Common European Framework of Reference for Languages, for comprehension, written and oral production. Response time was checked for each skill block.

\section{Conclusion}

The project allowed for pedagogical innovation in HE in the teaching of FL in study cycles whose predominant training was not aimed at learning a specific foreign language. FLL (foreign language learning) took place on the basis of social, cultural and artistic stimuli and was promoted through content production in the context of linguistic and cultural diversity. It was also intended to encourage good interdisciplinary practices, consolidate knowledge and stimulate know-how in a collaborative and cooperative way; with the intention of strengthening multilingual and multicultural awareness among students, using, for this purpose, varied, creative and multimodal approaches. As a strategy inserted in the scope of communicative paradigms, digital storytelling allows for a reflection on the most appropriate processes for cognition and values the socio-cultural dimension, focusing on individual and collective identity, through the JASM project.

\section{References}

Anderson, Jim; Chung, Yu-Chiao; Macleroy, Vicky (2018). Creative and critical approaches to language learning and digital technology: findings from a multilingual digital storytelling project. Language and Education, vol.32, $\mathrm{n}^{\circ} .3,195-211$ https://doi.org/10.1080/09500782.2018.1430151 Retrieved 15.04.2021 from https://www.tandfonline.com/doi/pdf/10.1080/09500782.2018.1430151 ?needAccess $=$ true

Conselho da Europa (2007). Grupo de alto nível sobre o multilinguismo - Relatório Final (Resumo), 1-9.

Conselho da Europa (2018). Recomendação do conselho sobre as competências essenciais para a aprendizagem ao longo da vida. Jornal Oficial da União Europeia, (Edição em língua portuguesa), C189/1-C189/8.

Gaballo, Viviana. "Digital Language Teaching and Learning: A Case Study". Innovation in Language Learning. International conference. https://www.researchgate.net/publication/337415640_ Digital_Language_Learning_and_Teaching

JASM Project: Open Window onto the world: Foreign Languages, Multimodal Creativity and Pedagogical innovation in Higher Education. https://www.esev.ipv.pt/jasm/

Morgado, M. (2019). Competências para gerir a diversidade e a interculturalidade. Exedra, Revista Científica ESEC, número temático EIPE2019, 11-27.

Piccardo, E. (2013). "Plurilingualism and Curriculum Design: Toward a Synergic Vision". TESOL Quarterly, 47(3), Sept.:600-614.

Reinders, Hayo. "Digital Storytelling in the Foreign Language Classroom". ELTWorld online.com, april 11, vol. 3.1-9. Retrieved 15.04.2021 from https://www.researchgate.net/publication/ 323186783_Digital_Storytelling_in_the_Foreign_Language_Classroom

Robin, Bernard R. "The Educational Uses of Digital Storytelling". Society for Information Technology \& Teacher Education International Conference, Mar 19, 2006 in Orlando, Florida, USA Association for the Advancement of Computing in Education (AACE), Waynesville, NC USA. ISBN 978-1-880094-58-7 https://www.learntechlib.org/primary/p/22129/

Valença, Marcelo M.; Tostes, Ana Paula Balthazar (2019). "O storytelling como ferramenta de aprendizado ativo". Revista Carta Internacional. Belo Horizonte, vol. 14, $\mathrm{n}$ 2, 221-243. Retrieved 30.03.2021 from https://www.researchgate.net/publication/335469301_O_Storytelling_como_ferramenta_de_apren dizado_ativo 